\section{International Journal of Medical Research and Review}

\title{
Tunica vaginalis flap - is it a better surgical choice for urethro- cutaneous fistula following circumcision?
}

\author{
Maity K. ${ }^{1}$, Kumar Pal D. ${ }^{2 *}$
}

DOI: https://doi.org/10.17511/ijmrr.2020.i02.03

\footnotetext{
${ }^{1}$ Krishnendu Maity, Department of Urology, IPGMER and SSKM Hospital, Kolkata, West Bengal, India.

2* Dilip Kumar Pal, Department of Urology, IPGMER and SSKM Hospital, Kolkata, West Bengal, India.
}

Objective: To study the effectiveness of tunica vaginalis flap in repair of post circumcision urethrocutaneous fistula. Materials and Methods: The current study reviewed all patients having surgical repair of post-circumcision urethrocutaneous fistula from December 2014 to April 2019 at our institution. Results: Ten cases presenting at age 5 to 22 years were operated. Most [60\%] of the circumcisions were performed by a doctor at peripheral hospitals and others were done by traditional circumcisers. All cases had a single fistula and the size was more than $5 \mathrm{~mm}$ in all cases. Threelayered fistula closure was done in all cases using the tunica vaginalis flap as the second layer for closure. There was no recurrence in any case. Conclusion: Use of Tunica vaginalis flap for repair of post circumcision urethro-cutaneous fistula is a highly effective technique regardless of size and site of the fistula. It is a simple procedure without any postoperative complications and without any recurrence.

Keywords: Circumcision, Complication, Repair, Tunica-vaginalis flap, Urethrocutaneous fistula

Corresponding Author

Dilip Kumar Pal, , Department of Urology, IPGMER and SSKM Hospital, Kolkata, West Bengal, India.

Email: urologyipgmer@gmail.com
How to Cite this Article

To Browse

Maity K, Pal DK. Tunica vaginalis flap - is it a better surgical choice for urethro-cutaneous fistula following circumcision?. Int J Med Res Rev. 2020;8(2):154158.

Available From

https://ijmrr.medresearch.in/index.php/ijmrr/article/ view/1141

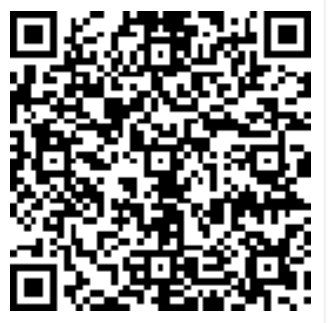

Manuscript Received 2020-03-20

Conflict of Interest No
Review Round 1 2020-03-30

Funding
Review Round 2

2020-04-04

Ethical Approval

Yes
Review Round 3

Accepted 2020-04-09

Plagiarism X-checker $9 \%$

Note

(c) 2020 by Krishnendu Maity, Dilip Kumar Pal and Published by Siddharth Health Research and Social Welfare Society. This is an Open Access article licensed under a Creative Commons Attribution 4.0 International License https://creativecommons.org/licenses/by/4.0/ unported [CC BY 4.0]. 


\section{Introduction}

Circumcision is the surgical procedure that involves removal of the skin coveringthe tip of the penis, also called preputium, baring the glans penis. Most commonly circumcision is performed because of religious causes, followed by refractory cases of physiological phimosis.

There remains a lot of controversy regarding benefits of circumcision, however,because of some ofits approved benefits likeprevention of HIV transmission, helping in urination, decreasing the risk of paraphimosis, decreasing cancer risk, giving good cosmetic image, and maintaining penile hygiene, it has been accepted [1].

Like any other surgical procedure circumcision also have many complications however bleeding and infection are major complication [2,3]. Urethrocutaneous fistula, not a very common complication, in developed countries, however, sub-Saharan and underdeveloped countries report a high rate of urethro-cutaneous fistulafollowing circumcision, mainly because of unsterile conditions and performance of the procedure by untrained persons $[4,5,6]$.

Surgical repair is necessary for treatment and different techniques described for repair include primary closure,modified Mathieu's technique using dartos muscle flap, and Snodgrass repair [7]. Tunica vaginalis flap is a versatile flap readily available, easy to obtain without causing any harm to the testis, and has been already in use for hypospadias repair. The present study tried to utilize this versatile flap for repair of urethro-cutaneous fistulas as this flap has shown very good results in hypospadias surgery.

The main purpose of this study is to highlight the effectiveness of tunica vaginalis flap repair as an easy acceptable alternative to accepted surgical techniques of post circumcision urethro-cutaneous fistula repair.

\section{Materials and Methods}

Setting: Patients of urethro-cutaneous fistula coming to the urology OPD of SSKM Hospital

Duration of study: December 2014 to April 2019

Type of study: Retrospective Inclusion criteria: All patients with post
Exclusion criteria: Patients not giving consent

Data collection: Performed using parameters of patients age of circumcision and presentation, method of circumcision, circumcisers, number, location and sizes of fistulae, the techniques of repair and postoperative outcome

Surgical procedure: Delayed repair in all cases was performed under general anesthesia. Ceftriaxone $50 \mathrm{mg} / \mathrm{kg}$ was given as prophylactic at the induction of anesthesia. The pubic, penile, and perineal regions were properly cleaned and scrubbed before the operation. The operative field was painted with a povidone-iodine solution from the upper abdomen to mid-thighs. Drapes were placed, exposing only the penile region. A stay suture, silk 4/0 on around bodied needle, was taken from the glans vertically.

A silicon catheter was placed in the bladder per urethra. A tourniquet was applied at the base of the penis. The fistula was marked and an elliptical incision was made around it. The skin around the fistula was undermined. Tunica vaginalis flap dissected. The fistula was repaired using Vicryl 6/0 on around bodied needle, by turning down the edges of the urethra. The edges were completely inverted in a watertight fashion.

The suture line was covered by tunica vaginalis flap brought in the field through a tunnel in the skin, taking care not to superimpose the suture line. A rotational skin flap was brought over the dartos flap as a third layer. Bipolar diathermy was minimally used for hemostasis.

The tourniquet was removed and gelonet dressing was placed, covered by gauze dressing. The dressing was changed on the second post-operative day. The catheter was retained for seven days

Ethical consideration: Ethical clearance taken from the ethical committee of SSKM Hospital

Statistical analysis: performed using IBM SPSS 19 software

\section{Results}

Ten patients underwent tunica vaginalis flap repair for post circumcision urethra-cutaneous fistula during the mentioned time period in our hospital.

The clinical characteristics of all these patients have been summarized in Table1. 
Table-1: Clinical characteristics of patients with post-circumcision urethrocutaneous fistula.

\begin{tabular}{|c|c|c|}
\hline Clinical variable & Frequency & Percentage \\
\hline Total patients & 10 & 100 \\
\hline \multicolumn{3}{|l|}{ Circumcisers } \\
\hline Doctor & 6 & 60 \\
\hline Traditionalist & 4 & 40 \\
\hline \multicolumn{3}{|l|}{ Age at circumcision } \\
\hline After 1 year & 10 & 100 \\
\hline \multicolumn{3}{|l|}{ Location of fistula } \\
\hline Corona & 10 & 100 \\
\hline \multicolumn{3}{|l|}{ Number of fistulae } \\
\hline One & 10 & 100 \\
\hline \multicolumn{3}{|l|}{ Size of fistula } \\
\hline$>5 \mathrm{~mm}$ & 10 & 100 \\
\hline \multicolumn{3}{|l|}{ Fistula surgery } \\
\hline Tunica vaginalis flap repair & 10 & 100 \\
\hline Recurrence & 0 & 0 \\
\hline
\end{tabular}

The patient's age at the time of presentation rangedbetween 5 years to 22 years with an average age of 12.5 years.

All 10 patients underwent circumcision for refractory phimosis and for religious reasons.

The patients who were circumcised by a doctor had the dissection method of circumcision, patients who were circumcised by traditional circumcisers got circumcised by some local surgical method, which could not be described properly by the patients, however, none was circumcised using any form of circumcision device.

Four [40\%] patients circumcisions wereperformed by atraditional circumciserand six (60 \%) were circumcised by a doctor.

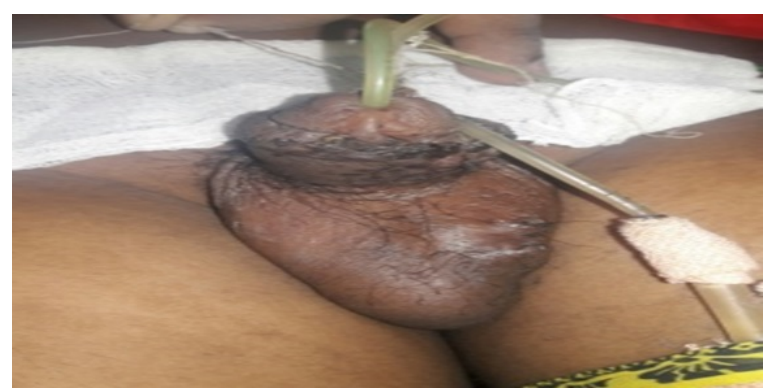

Fig-1: Pre-op picture.

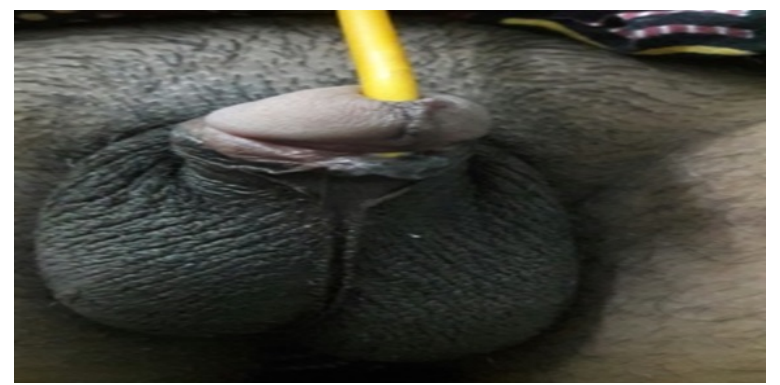

Fig-2: Immediate post-op.

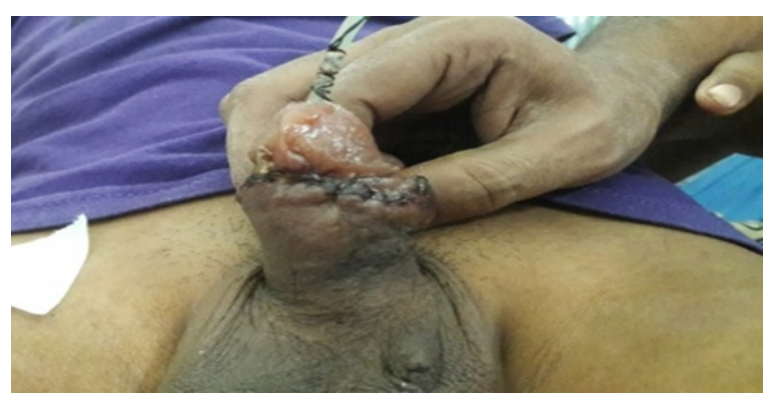

Fig-3: After 1 month.

All the cases had a single UCF, > $5 \mathrm{~mm}$ in size, and located in the coronal region [Figure 1]. In all cases, after degloving, the fistula was dissected all around, and using 5/0 polydioxanonesutures the closures were performed in three layers: Closure of fistula, tunica vaginalis flap layer closure, and finally skin closure. All of them were kept on per urethral catheterization for 10 days. Suprapubic diversion of urine was not donein any patient, following fistula closure. There was no recurrence of fistula in any case[Figure 2 and Figure 3].

\section{Discussion}

Circumcision, though one of the easiest and simplest operative procedures, is not without complications, and among its varied complications, one is a urethro-cutaneous fistula. After circumcisions, the reported complications rate is around is $0-30 \%$ [8]. Different reported complications include wound infection, sepsis, painful erection, concealed penis, incomplete circumcision [2]. However, one of the most troublesome is urethro-cutaneous fistula [9]. In India, mainly, Muslims practice male circumcision for cultural reasons [10]. No data is available in the literature regarding the complications of circumcision, age of circumcision, and the time of presentation in Indian children, however, the timing of circumcision and timing of presentation with complications in the present study was found to be 
Similar to other reported studies [11]. In all our cases, in which circumcision was performed by traditional circumcisers, the procedure was performed without giving anyanesthesia, which was reported by the mother; however, in the circumcisions done by the doctor, local anesthesia was used. Thus, urethral wall injury in an uncooperative patient with the wrong placement of sutures and quick clamping can be the cause of urethrocutaneous fistula in non-anesthesized cases. Other reasons described in the literature are taking a deep needle bite that engages urethra, the use of non- absorbable sutures, or carrying out the procedure in an unhygienic environment $[11,12,13,14,15]$. However, the most important factor as etiology of urethrocutaneous fistula remains lack of surgical skills especially if circumcision isbeing performed by poorly trained or untrainedhealth personnel, as found in the present study and has been seen in other studies [15]. After making the diagnosis, the selection of an appropriate method for repairing the fistula is important. Regarding the timing of repair of a fistula, in case of urethral injury noticed during the operation, repairing at the same session provides very good results [16].In the case of urethral injury noticed postoperatively, postponement of repair to at least 6 months gives better results, as the recommended time period helps in stopping and completely curing the inflammation [16]. In the present study time interval from injury to the presentation was more than 6 months for every patient as per the recommendation.Choosing the technique of repairdepends on factors like location, size, number of fistulae, and soft tissue availability for reinforcement of the repair. Multilayered tensionfree closure is usually the favored technique [17]. Ikuerowo et al [17] in his study repaired 31 cases of urethrocutaneous fistula following circumcision, in 9 patients he used simple closure technique, in 18 patients modified Mathieu repair [MMR] using dartos muscle flap and in 5 patients he used Snodgrass repair technique. He had fistula recurrence in 8 cases of MMR and 1 case of Snodgrass repair and all those cases had a fistula of $>5 \mathrm{~mm}$ size, however, the present study had no recurrence using tunica vaginalis flap technique and in all our cases the size of the fistula was $>5 \mathrm{~mm}$. In another study [18] using dartos pedicled flap repair was done for iatrogenic post circumcision fistula for 7 cases, with 1 recurrence in the postoperative period. So compared to other studies it is seen that tunica vaginalis flap can be used effectively for post circumcision urethrocutaneous fistulas of larqe size
With minimal recurrence.This flap is usually used after failed hypospadias surgery for repair of recurrent urethro-cutaneous fistulas and regardless of fistula location and number, type of initial hypospadias repair, and the number of previous closure attempts, this flap is highly effective [19] it is a simple procedure without any significant postoperative sequelae. In the present study had no recurrence, also there were no postoperative local complications. The present study encountered some limitations in this study like the small sample size of the study as post circumcision urethro-cutaneous fistula is not very common in our country, which might have resulted in zero postoperative recurrence rate.

\section{Conclusion}

UsingTunica vaginalis flap for repair of post circumcision urethro-cutaneous fistula is a highly effective technique regardless of size and site of the fistula. itis a simple procedure without any postoperative complications and without any recurrence as there were no postoperative complications or recurrence in the present study. It should be considered as an effective post circumcision urethrocutaneous fistula closure technique.

\section{What does the study add to the existing study}

This study has shown that tunica vaginalis flap is an excellent option for repair of post circumcision urethrocutaneous fistula without causing any harm to the testis and without any recurrence and can be considered as another surgical tool in the hands of urologists for treatment of post circumcision urethro-cutaneous fistula.

\section{Contribution}

Dr. KrishnenduMaity: Conception, design, and analysis Dr Pinaki Roy: Data collection, literature review, and writing Dr D. K. Pal: Supervision, critical review

\section{Reference}

01. Peng YF, Cheng Y, Wang GY, Wang SQ, Jia C, Yang $\mathrm{BH}$, et al. Clinical application of a new device for minimally invasive circumcision. Asian J Androl. 2008; 10(3)447-454.

doi: [Article] [Crossref] 
02. Senel FM, Demirelli M, Oztek S. Minimally invasive circumcision with a novel plastic clamp technique- a review of 7,500 cases. Pediatr Surg Int. $2010 ; 26(7) 739-745$.

doi: [Article] [Crossref]

03. Nandiolo KR. Complications of Ritual Male Circumcision in Developing Countries. J Urol Nephrol. 2018; 3(1)000134.

[Crossref]

04. Appiah KA, Gyasi-Sarpong CK, Azorliade R, Aboah K, Laryea DO, Otu-Boateng $\mathrm{K}$, et al. Circumcision-related tragedies seen in children at the Komfo Anokye Teaching Hospital, Kumasi, Ghana. BMC Urol. 2016;16(1)65. doi: [Article] [Crossref]

05. Ceylan K, Burhan K, Yilmaz Y, Can S, Kuş A, Mustafa G. Severe complications of circumcision- an analysis of 48 cases. J Pediatr Urol. 2007;3(1)32-35.

doi: [Article] [Crossref]

06. El-Bahnasway MS, El-Sherbiny MT. Pediatric penile trauma. B J U Int. 2002;90(1)92-96.

[Article] [Crossref]

07. Atıcı A, Çelikkaya ME, Akçora B. A rare complication following circumcision, severe urethral fistula located on the distal penile shaft and the coronal margin- A case report. Pedia Urol Case Rep. 2017;5(1)1-4.

doi: [Article] [Crossref]

08. Weiss HA, Larke N, Halperin D, Schenker I. Complications of circumcision in male neonates, infants and children- a systematic review. BMC Urol. 2010;10;1.

doi: [Article] [Crossref]

09. Osifo OD, Odion-Obomhense $H$, Osagie TO. Repair-oriented categorization of circumcision urethral injury in Benin city, Nigeria. J Pediatr Urol. 2013;9(2)206-211.

doi: [Article] [Crossref]

10. Madhivanan $\mathrm{P}$, Krupp $\mathrm{K}$, Chandrasekaran $\mathrm{V}$, Karat SC, Reingold AL, Klausner JD. Acceptability of male circumcision among mothers with male children in Mysore, India. AIDS (London, England). 2008;22(8)983-988. doi: [Article] [Crossref]

11. Mckony CA, Aboud M. Post-Circumcision Urethro-Cutaneous Fistula- The Key to Successful Reconstruction. East Central Afr J Surg. 2006;11(1)118-120.

[Crossref]
12. Baskin LS, Canning DA, Snyder HM 3rd, Duckett JW Jr. Surgical repair of urethral circumcision injuries. J Urol. 1997;158(6)2269-2271. doi: [Article] [Crossref]

13. Sherman J, Borer JG, Horowitz M, Glassberg KI. Circumcision Successful glanular reconstruction and survival following traumatic amputation. J Urol. 1996;156(2 Pt 2)842-844. doi: [Article] [Crossref]

14. Yilmaz AF, Sarikaya S, Yildiz S, Buyukalpelli R. Rare complication of circumcision- Penile amputation and reattachment. Eur Urol. $1993 ; 23 ; 423-424$. doi: [Article] [Crossref]

15. Osifo OD, Oriaifo IA. Circumcision mishaps in Nigerian children. Ann Afr Med. 2009;8(4)266270. doi: [Article] [Crossref]

16. Dieth AG, Moh-Ello $N$, Fiogbe $M$, Yao $\mathrm{KJ}$, Tembely $S$, Bandre $E$ et al. Accidents of circumcision in children in Abidjan, Côte d'Ivoire [in French]. Bull Soc Pathol Exot. 2008;101(4)314-315.

doi: [Article] [Crossref]

17. Ikuerowo SO, Bioku MJ, Omisanjo OA, Esho JO. Urethrocutaneous fistula complicating circumcision in children. Niger J Clin Pract. 2014;17(2)145-148.

doi: [Article] [Crossref]

18. Khan I, Qureshi MA, Abbas SH, Shaukat $M$. Management of Post-traumatic and Iatrogenic urethro cutaneous fistula in children (a case series of seven patients). JPMA- J Pak Med Assoc. 2018;68(6)955-958.

[Crossref]

19. Kadian YS, Rattan KN, Singh J, Singh M, Kajal P, Parihar D. Tunica vaginalis- an aid in hypospadias fistula repair: our experience of 14 cases. Af J Paed Surg. 2011;8(2)164-167. doi: [Article] [Crossref] 